\title{
THE EFFECT OF CURING TEMPERATURE ON THE PROPERTIES AND STRUCTURE OF GEOPOLYMER COMPOSITE BASED ON POTASSIUM SILICATE AND METAKAOLIN
}

\author{
ZDENĚK MAŠEK, ${ }^{\# L I N D A ~ D I B L I ́ K O V A ́ ~}$ \\ Výzkumný a zkušebni letecký ústav - Composite Technologies Department, \\ Beranových 130, 19005 Prague, Czech Republic \\ ${ }^{\#}$ E-mail: diblikova@vzlu.cz
}

Submitted December 21, 2017; accepted May 22, 2018

\begin{abstract}
Keywords: Geopolymer, Curing, Storage modulus, NMR MAS spectroscopy, X-ray diffraction
A carbon fibre/geopolymer composite whose matrix was based on potassium silicate and metakaolin was subjected to different curing temperature modes. The effect of the treatments was evaluated by testing the stiffness and water uptake resistance of the composite. The structure of the composites was analysed by scanning electron microscopy, X-ray diffraction and nuclear magnetic resonance. It was determined that the highest stiffness was achieved by the primary curing at $80^{\circ} \mathrm{C}$. Contrary to this, curing at temperatures higher than $100^{\circ} \mathrm{C}$ increased the resistance to water uptake, resulting in smaller decrease in the storage modulus. Structural changes of the geopolymer were linked to the course of the curing temperature mode. Two types of the curing were suggested for the use of the carbon fibre/geopolymer composite in heat stress applications and in a humid environment, respectively.
\end{abstract}

\section{INTRODUCTION}

Geopolymer resin is a heterogeneous system consisting of solid particles with a mean size of about three micrometres, which polymerises by means of a watergenerating condensation mechanism and that is cured in a strongly alkaline environment. The process of geopolymer curing, according to current knowledge, is based on the formation of a polymeric spatial structure formed by silicon and aluminium atoms coordinated by oxygen atoms acting as bridges. The ratio between the silicon and aluminium atoms is usually at least one, i.e., $\mathrm{Si} / \mathrm{Al}>1$. The composition of the geopolymer resin is, according to convention, expressed using the following empirical formula: $\mathrm{M}_{\mathrm{x}}\left(-\left(\mathrm{SiO}_{2}\right)_{\mathrm{y}} \mathrm{AlO}_{2}\right) \cdot \mathrm{nH}_{2} \mathrm{O}$, where $M$ is an alkali ion and $x, y$ and $n$ give the molar representation of the respective atoms [1]. The equivalent expression using molar ratios is $\mathrm{M}_{2} \mathrm{O}: \mathrm{Al}_{2} \mathrm{O}_{3}=\mathrm{x}, \mathrm{SiO}_{2}: \mathrm{Al}_{2} \mathrm{O}_{3}=2 \mathrm{y} / \mathrm{x}$ and $\mathrm{H}_{2} \mathrm{O}: \mathrm{Al}_{2} \mathrm{O}_{3}=\mathrm{n}$. The empirical formula suggests that it is a structure composed of spatially structured chains of tetrahedra of aluminium and silicon atoms. These tetrahedra are connected through their vertices, not through their edges. Chains of tetrahedra form an irregular spatial network, with alkali ions and water molecules in the gaps. The strength of the bond of the water molecules to the spatial network is not constant. The formula further indicates that it is a non-stoichiometric compound. The structure loses water by drying; microstructures are formed in the structure and the material becomes harder and more brittle. The ratio between the atoms of alkali and aluminium in the structure is significant. This ratio should be $0.8<\mathrm{K}_{2} \mathrm{O} / \mathrm{Al}_{2} \mathrm{O}_{3}<1.2$ [1]. Small ratios can reduce the conversion during a geopolymerisation reaction, while large ratios lead to the generation of free alkali and white efflorescence of alkali carbonates. The structure of the geopolymer network was designed by Davidovits and Barbosa [1,2]. The greatest breakthrough in the study of the structure occurred through the analysis of the aluminosilicate spectra by nuclear magnetic resonance (NMR). For the first time, this method was mentioned in the work of Lippmaa et al. [3], which dealt with a chemical shift of crystalline silicates and aluminosilicates.

They assume that aluminosilicates are formed by covalent bonds between silicon atoms and aluminium, with oxygen atoms being the bridge. The silicon atom is then surrounded by other silicon or aluminium atoms in the second sphere. They found that the number of aluminium atoms in the second sphere of the coordination is proportional to the chemical shift in the spectrum ${ }^{29} \mathrm{Si}$ NMR. Similarly, in the case of ${ }^{27} \mathrm{Al}$, the study of the solutions of polyaluminates and aluminosilicates established that the chemical shift of ${ }^{27} \mathrm{Al}$ is dependent on the coordination of the aluminium atoms by the oxygen atoms. This was reported for the first time in $[4,5]$. Another important finding of the study of the structure of aluminosilicates is the Loewenstein rule, which forbids the connection of an aluminium atom in the second sphere of the coordination to another aluminium atom [6]. 
A geopolymer resin can be used to prepare composites reinforced with various kinds of fibres. One of the commonly used manufacturing technologies of conventional organic composites can be applied to the geopolymer composite preparation. It is the manual lamination intensified by placing the prepared reinforcement/matrix structure in a plastic bag under a vacuum, the so called vacuum bagging. In this work, we aimed at optimising the curing process of the geopolymer composite prepared by lamination of a carbon fabric using vacuum bagging.

The preparation of carbon fibre/geopolymer composite using vacuum bagging together with curing at $80-85^{\circ} \mathrm{C}$ was reported in [7]. The authors also discuss the necessity of drying the composite to remove the contained water and the size of geopolymer resin particles, which makes it difficult to penetrate into the bundles of carbon fibres. A geopolymer composite with 3.5 - 7.5 wt. \% of short carbon fibres was prepared in a mould, cured during vacuum bagging at $80^{\circ} \mathrm{C}$ and then dried at $120^{\circ} \mathrm{C}$ [8]. A maximum flexural strength of $0.097 \mathrm{GPa}$ was reached for the fibre content of $4.5 \%$.

Foden et al. used a slightly modified process as they dried each fabric layer saturated with the geopolymer resin for $30 \mathrm{~s}$ at $80^{\circ} \mathrm{C}$ before lamination [9]. Curing was undertaken at $80^{\circ} \mathrm{C}$ during vacuum bagging. The composite was pressed for three hours and, finally, dried at $80^{\circ} \mathrm{C}$ for 24 hours. The rather complicated curing process is described in [10]. It is comprised of the preparation of the prepreg, its layering, which is interrupted by 10 -minute intervals of drying at $65^{\circ} \mathrm{C}$. The resulting composite was cured in a vacuum at $65^{\circ} \mathrm{C}$, taken out of the vacuum and then gradually dried at 95 , 135 and $205^{\circ} \mathrm{C}$. Thang et al. [11] mixed geopolymer resin with $\mathrm{Al}_{2} \mathrm{O}_{3}$ nano-fibres and the resulting resin was used to impregnate the carbon fabric. In this case, the vacuum bagging started at the laboratory temperature and then it was raised to $80^{\circ} \mathrm{C}$. The final drying of the composite was performed at $80^{\circ} \mathrm{C}$ at a normal pressure. The combination of the geopolymer resin and a chopped basalt fibre, in the concentration up to $10 \mathrm{wt}$. \%, was tested in [12]. The mixture was cured in a silicon mould at $50^{\circ} \mathrm{C}$ for 24 hours. The exposition of the composite at $500^{\circ} \mathrm{C}$ had a negative effect on the bending strength which was reduced by $75 \%$.

The stated works dealing with the preparation of fibre reinforced geopolymer composites present certain general features, such as:

- use of low viscosity resin,

- absence of particle fillers,

- the requirement of the smallest possible particles,

- use of nano-fibres in order to reduce the cracks in the matrix,

- preventing water evaporation during the first phase of curing and drying in the following curing phase.
In this paper, a geopolymer synthesised from the following raw materials was studied:

- a potassium silicate solution with a high content of dry matter and a high modulus, i.e., a molar ratio of $\mathrm{SiO}_{2} / \mathrm{K}_{2} \mathrm{O}$,

- an amorphous silica, which is produced as waste from zirconium production,

- a finely ground burnt clay shale as the source of the aluminium component.

It was shown that the selection of a suitable curing temperature mode has a significant effect on the properties of the resulting geopolymer composite. This was demonstrated by testing the composite strength and the resistance against the effects of boiling water.

\section{EXPERIMENTAL}

\section{Materials}

The geopolymer resin was prepared by alkaline activation of the burnt clay shale Mefisto L05 (České lupkové závody, a.s., Czech Republic) and an amorphous silica (Thermal silica, Saint-Gobain, France). The alkali activator of the reaction was an aqueous solution of potassium silicate DV 1.7 (Vodní sklo, a.s., Czech Republic). The ratio of the raw materials was set according to our previous development of the geopolymer with the best strength properties; the exact chemical composition is classified information within the project.

A Dispermat CA60-M1 (VMA-GETZMANN $\mathrm{GmbH}$, Germany) with a gear wheel of $40 \mathrm{~mm}$ in diameter was used for mixing the raw materials. The mixing vessel was placed in a container cooled by running water. First, the amorphous silicon dioxide was mixed for 20 minutes at $9600 \mathrm{rpm}$ in a solution of potassium silicate cooled to $3{ }^{\circ} \mathrm{C}$, the mixture was cooled at $-20^{\circ} \mathrm{C}$ for 20 minutes and then metakaolin was mixed in it for 5.5 minutes at $9600 \mathrm{rpm}$ and finally, the mixture was placed in a freezer for $10 \mathrm{~min}$ and then degassed by stirring in a vacuum.

\section{Preparation of the composite specimens}

The geopolymer resin was applied manually with a spatula to ten layers of carbon fabric in the form of a plain weave with a surface density of $93 \mathrm{~g} \cdot \mathrm{cm}^{-2}, 1 \mathrm{~K}$ (Havel Composite CZ s.r.o.), at a dosage of $282 \mathrm{~g}$ per square metre of the fabric. The pieces were layered and pressed by rolling and the last layer was covered with P3 perforated separation foil and a non-woven distribution fabric. The plate was then enclosed in a PP foil and a vacuum was generated inside. The vacuum was maintained for 72 hours at $23^{\circ} \mathrm{C}$. The cured plate was cut into test pieces with dimensions of $10 \times 80 \times 1.7 \mathrm{~mm}$. 
The dimensions were selected to suit the dynamic mechanical analyser (DMA) and the low thickness of the sample also showed greater sensitivity to the corrosion processes when the samples were exposed to boiling distilled water.

The test specimens were primarily cured at $80^{\circ} \mathrm{C}$ for 18 hours, then weighed, and their storage modulus was measured. Then they were divided into eight groups, A1 to $\mathrm{A} 8$, each of which was subjected to a higher thermal exposure. Group $\mathrm{A} 1-100^{\circ} \mathrm{C} / 2$ hours, $\mathrm{A} 2-100^{\circ} \mathrm{C} / 2$ hours $+110^{\circ} \mathrm{C} / 2$ hours and so on, according to Tables 1 and 2 . After the thermal exposure, the storage modulus and the changes in the weight of the pieces were measured and the pieces were exposed to boiling distilled water. After the water uptake resistance and dry weight had been measured, the storage modulus was measured again.

\section{Characterisation of the geopolymer resin and composite}

To study the microstructure of the pure geopolymer resin, a cylinder $40 \mathrm{~mm}$ in diameter and $3 \mathrm{~mm}$ thick was prepared, cured at $80^{\circ} \mathrm{C}$, broken and a shard was analysed. To study the carbon fibre/geopolymer composite, a small piece was cut off and analysed. The analysis of the microstructures of the geopolymer composites was performed by scanning electron microscopy (SEM) using a Vega3SBU scanning electron microscope (Tescan, Czech Republic) at an accelerating voltage of $30 \mathrm{kV}$ in the mode of back-scattered electrons (BSE) and at a low pressure (20 to $30 \mathrm{~Pa}$ ) and a working distance of 6 to $15 \mathrm{~mm}$.

$\mathrm{X}$-ray diffraction was used to analyse the metakaolin structure of the Mefisto L05 and Thermal Silica as the source material and the pure resin powder sample that had been cured at $80^{\circ} \mathrm{C}$ for 18 hours; the measurement was performed at room temperature. The measurement was made using a PANalytical PW 3040 X-ray diffractometer with $\mathrm{CuK} \alpha$ radiation $(\mathrm{K}-\mathrm{Alpha} 1=1.54060 \AA$, $\mathrm{K}$-Alpha2 $=1.54443 \AA, \mathrm{U}=40 \mathrm{kV}, \mathrm{I}=30 \mathrm{~mA}, \mathrm{~K}-\mathrm{A} 2 /$ $\mathrm{K}-\mathrm{A} 1$ ratio $=0.50)$ with an $\mathrm{X}^{\prime}$ Celerator detector. The output was processed with the software High Score Plus.

The elemental composition of the raw materials was determined by X-ray fluorescence using the PANalytical AXIOS $3 \mathrm{~kW}$ with a Rh SST-mAX anode and a dispersing crystal LiF220, GE, PE002, PX1. The output was determined by a fundamental parametric method based on six measured scans. The PANalytical ICSD FIZ Karlsruhe 2012 mineral database was used to interpret the spectra.

The nuclear magnetic resonance measurement was performed using a Bruker Avance II HD500 WB/US-NME (Karlsruhe, Germany) on a rotating sample at a frequency of $5-10 \mathrm{kHz}$ and with the axis of rotation at an angle to the vector of the magnetic induction (MAS - magnetic angle spinning). The sample was placed in a 4-mm $\mathrm{ZrO}_{2}$ rotor and exposed to a standard single pulse. During the data transfer, SPINAL 64 dipolar decoupling was applied to eliminate the spin-spin interaction. The flip pulse length was $4.8 \mu \mathrm{s}$. The nutation frequency of the B1 excitation field $\left({ }^{29} \mathrm{Si}\right.$ and $\left.{ }^{27} \mathrm{Al}\right)$ was $62.5 \mathrm{kHz}$ and the repetition interval was $4 \mathrm{~s}$. The atoms of ${ }^{29} \mathrm{Si}$ and ${ }^{27} \mathrm{Al}$ were calibrated by $\mathrm{M}_{8} \mathrm{Q}_{8}$ and $\mathrm{AlNO}_{3}$ as external standards ( -109.8 and $0.0 \mathrm{ppm}$, respectively). The samples were converted to powder form by grinding them in a porcelain mortar.

Table 1. Storage modulus and weight loss depending on curing in the range of 100 to $170^{\circ} \mathrm{C}$, the dwell time was 2 hours; $100 \%$ weight corresponds to the condition after primary curing.

\begin{tabular}{|c|c|c|c|c|c|c|c|c|}
\hline Set of samples & A1 & A2 & A3 & A4 & A5 & A6 & A7 & A8 \\
\hline \multirow{2}{*}{ Temperature exposure } & \multicolumn{7}{|c|}{$80^{\circ} \mathrm{C} / 18 \mathrm{~h}$} & \\
\hline & $100^{\circ} \mathrm{C}$ & $110^{\circ} \mathrm{C}$ & $120^{\circ} \mathrm{C}$ & $130^{\circ} \mathrm{C}$ & $140^{\circ} \mathrm{C}$ & $150^{\circ} \mathrm{C}$ & $160^{\circ} \mathrm{C}$ & $170^{\circ} \mathrm{C}$ \\
\hline Modulus after curing at $80^{\circ} \mathrm{C}$ [GPa] & 29.18 & 32.05 & 31.6 & 30.34 & 31.42 & 29.98 & 29.95 & 31.84 \\
\hline Modulus after target curing [GPa] & 28.45 & 30.82 & 30.23 & 28.24 & 27.96 & 26.84 & 25.76 & 25.85 \\
\hline Wt. after target curing [\%] & 98.78 & 98.49 & 98.02 & 97.55 & 96.84 & 96.87 & 96.07 & 95.90 \\
\hline
\end{tabular}

Table 2. Corrosion test in boiling distilled water and the effect on the modulus size depending on curing at 100 to $170^{\circ} \mathrm{C}$, while maintaining each temperature for 2 hours.

\begin{tabular}{lcccccccc}
\hline Set of samples & $\mathrm{A} 1$ & $\mathrm{~A} 2$ & $\mathrm{~A} 3$ & $\mathrm{~A} 4$ & $\mathrm{~A} 5$ & $\mathrm{~A} 6$ & $\mathrm{~A} 7$ & $\mathrm{~A} 8$ \\
\hline Temperature exposure & \multicolumn{7}{c}{$80^{\circ} \mathrm{C} / 18 \mathrm{~h}$} \\
\cline { 2 - 9 } & $100^{\circ} \mathrm{C}$ & $110^{\circ} \mathrm{C}$ & $120^{\circ} \mathrm{C}$ & $130^{\circ} \mathrm{C}$ & $140^{\circ} \mathrm{C}$ & $150^{\circ} \mathrm{C}$ & $160^{\circ} \mathrm{C}$ & $170^{\circ} \mathrm{C}$ \\
\hline Modulus before test [GPa] & 28.45 & 30.82 & 30.23 & 28.24 & 27.96 & 26.84 & 25.76 & 25.85 \\
\hline Modulus after drying [GPa] & 0.81 & 1.45 & 1.74 & 3.04 & 5.5 & 7.24 & 12.32 & 15.19 \\
\hline Wt. before test [\%] & 98.93 & 98.67 & 98.17 & 97.7 & 97.09 & 97.09 & 96.25 & 96.07 \\
\hline Wet wt. [\%] & 140.2 & 135.5 & 128.1 & 114.5 & 108.3 & 103.1 & 99.19 & 98.5 \\
\hline Dry wt. [\%] & 75.65 & 77.95 & 79.87 & 83.7 & 84.16 & 85.6 & 88.65 & 89.79 \\
\hline
\end{tabular}


Testing of the geopolymer composite

The non-destructive measurement of the storage modulus was performed using a DMA Q800 (TA Instruments, USA) at a frequency of $1 \mathrm{~Hz}$ and a strain amplitude of $20 \mu \mathrm{m}$. The storage modulus is the real part of the complex modulus of elasticity and is related to the sample's stiffness.

The test of immersing the specimens in boiling distilled water for $150 \mathrm{~min}$ allowed the evaluation of the behaviour of the composites prepared by carbon fabric lamination, which tend to form a high internal surface between the fibres and the polymer that contributes to the reduced resistance to aggressive water. The amount of absorbed water was determined immediately after the sample had been pulled out of the water (wet weight) and after drying at $105^{\circ} \mathrm{C}$ (dry weight) and the weight loss resulting from the dissolution of the polymer was measured. This test documents the degree of the crosslinking of the polymer, where the non-cross-linked polymer swells by absorbing water and disintegrates.

\section{RESULTS AND DISCUSSION}

Influence of curing on the strength and corrosion properties

The storage modulus of the $\mathrm{CF} /$ geopolymer composite after primary curing is $30.80 \mathrm{GPa}$ on average as can be seen in Table 1 . After the consequent curing steps in the range of 100 to $170^{\circ} \mathrm{C}$, the storage modulus gradually decreases; the greatest loss, $6 \mathrm{GPa}$, was determined at $170^{\circ} \mathrm{C}$, which was more than eight times the loss at $100^{\circ} \mathrm{C}$. The storage modulus is assumed to document both the degree of curing of the polymer and the quality of the adhesion between the matrix and the fibre reinforcement. Thus, the loss of stiffness shows that the connection between the fibre and the geopolymer was

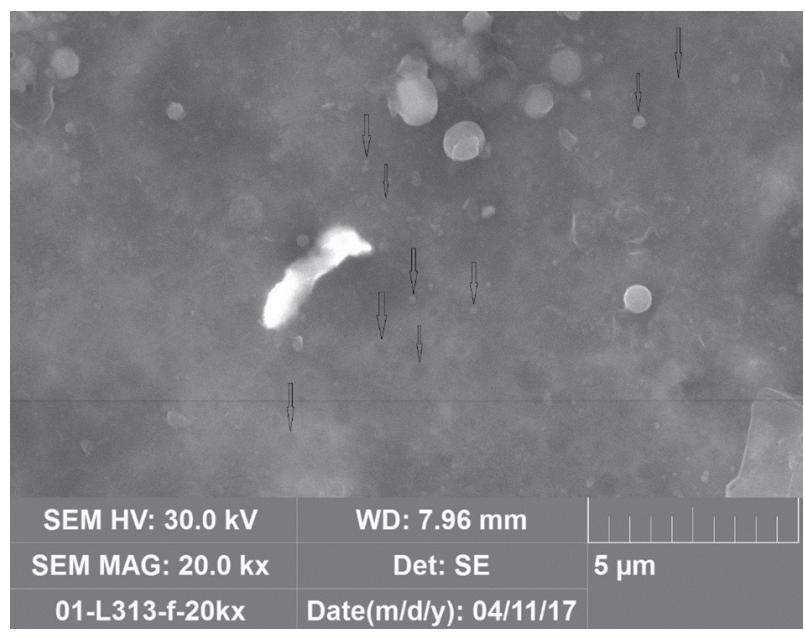

Figure 1. SEM image of the fracture surface of the pure geopolymer; the spherical structures are marked by arrows. subject to structural changes and that the geopolymer itself was subject to changes, which is also indicated by the differences in weight.

The opposite effect of the temperature was observed in the corrosion test, as stated in Table 2. The wet weight values show that with an increase in the temperature at which the geopolymer samples were cured, the water absorption of the samples decreased. The best result was achieved when curing was performed at the maximum temperature of $170^{\circ} \mathrm{C}$; the weight gain in this sample was

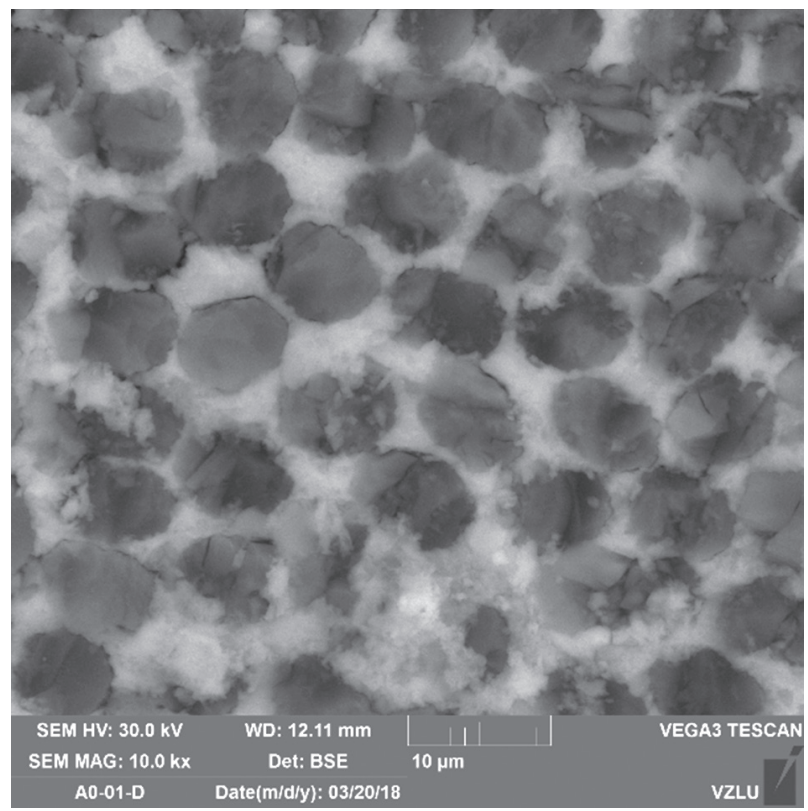

a)

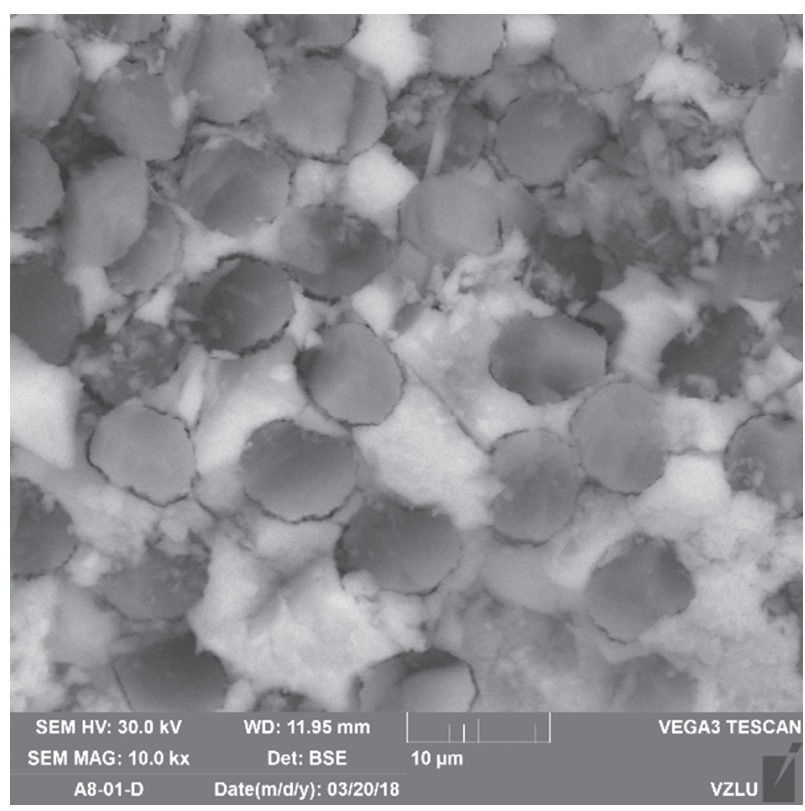

b)

Figure 2. SEM images of the structure of the section of the composite $\mathrm{A} 0$ (a) and $\mathrm{A} 8$ (b) cured at 80 and $170^{\circ} \mathrm{C}$, respectively, acc. to Table 2; the fibres are oriented perpendicularly to the section. 
only $2.4 \%$. On the other hand, at a curing temperature of $100^{\circ} \mathrm{C}$, the weight of the composite grew by more than $40 \%$, which indicates that a composite of resin cured at this temperature would be very sensitive to moisture. The effect of increasing the curing temperature is also confirmed by the comparison of weight and mechanical changes after drying the wet samples at $105^{\circ} \mathrm{C}$. The least affected sample was the one cured at $170^{\circ} \mathrm{C}$, where the weight decreased by $6 \%$ and the modulus by $41 \%$, while in the sample cured at $100^{\circ} \mathrm{C}$, the weight decreased by $23 \%$ and the modulus by as much as $97 \%$.

\section{Influence of curing on the geopolymer structure}

The cured resin resembles that of ceramics; its shard is smooth and vitreous. The curing process of the continuous phase of the pure geopolymer is documented in Figure 1. The microstructure of the pure geopolymer appears to be a homogeneous phase containing slightly visible spherical structures about $0.5 \mu \mathrm{m}$ in diameter (i.e., within the resolution of the microscope). The comparison of two composite samples with different degrees of curing is shown in Figure 2. Sample A0 was cured at $80^{\circ} \mathrm{C}$ for 18 hours. Sample A8 was cured according to the procedure in Table 2. A light matrix surrounding dark fibres can be seen in both micrographs. The separation of the fibres from the matrix is more pronounced on the fracture surface of sample A8. Moreover, the fracture surfaces of the sample A0 matrix seem jagged, while those of sample A8 are more compact.

It was determined by X-ray powder diffraction that the burnt clay shale Mefisto L05 contained an amorphous phase with an admixture of quartz and a small amount of minerals - mullite, kaolinite, biotite, and anatase
(Figure 3). The thermal silica showed an amorphous phase with traces of $\mathrm{ZrO}_{2}$ (Figure 4). The structure of the cured geopolymer is formed by an amorphous halo between 2 Theta $20^{\circ}$ and $35^{\circ}$ and there are also traces of the minerals originating from the raw materials present as displayed in Figures 5 and 6. No additional crystalline phases which would be generated during curing were identified in the geopolymer. The highest qualitative portion of the Mefisto L05 crystalline phase is represented by quartz, other minerals are present in an insignificant amount.

$\mathrm{X}$-ray fluorescence confirmed the presence of $\mathrm{ZrO}_{2}$ in the Thermal Silica. Moreover, procedure determined not a negligible amount of amorphous $\mathrm{Al}_{2} \mathrm{O}_{3}$, which was

Table 3. X-ray fluorescence analysis of the solid components of the raw materials and the cured geopolymer (wt. \%); $\mathrm{H}_{2} \mathrm{O}$ not included.

\begin{tabular}{lccc}
\hline Component & $\begin{array}{c}\text { Thermal } \\
\text { Silica }\end{array}$ & $\begin{array}{c}\text { Mefisto } \\
\text { L05 }\end{array}$ & $\begin{array}{c}\text { Geopolymer } \\
80^{\circ} \mathrm{C}\end{array}$ \\
\hline $\mathrm{SiO}_{2}$ & 92.6 & 49.1 & 64.9 \\
$\mathrm{Al}_{2} \mathrm{O}_{3}$ & 4.04 & 47.3 & 14.0 \\
$\mathrm{Fe}_{2} \mathrm{O}_{3}$ & 0.21 & 0.90 & 0.46 \\
$\mathrm{CaO}$ & 0.04 & 0.20 & 0.10 \\
$\mathrm{MgO}$ & - & 0.10 & - \\
$\mathrm{K}_{2} \mathrm{O}$ & 0.08 & 0.50 & 17.4 \\
$\mathrm{Na}_{2} \mathrm{O}$ & 0.10 & - & 0.42 \\
$\mathrm{TiO}_{2}$ & 0.06 & 1.60 & 0.57 \\
$\mathrm{ZrO}_{2}$ & 1.85 & - & 1.35 \\
$\mathrm{SO}_{3}$ & 0.01 & 0.10 & 0.07 \\
$\mathrm{P}_{2} \mathrm{O}_{5}$ & 0.40 & - & 0.20 \\
$\mathrm{As}_{2} \mathrm{O}_{3}$ & 0.13 & - & - \\
not ident. & 0.48 & 0.20 & 0.53 \\
\hline
\end{tabular}

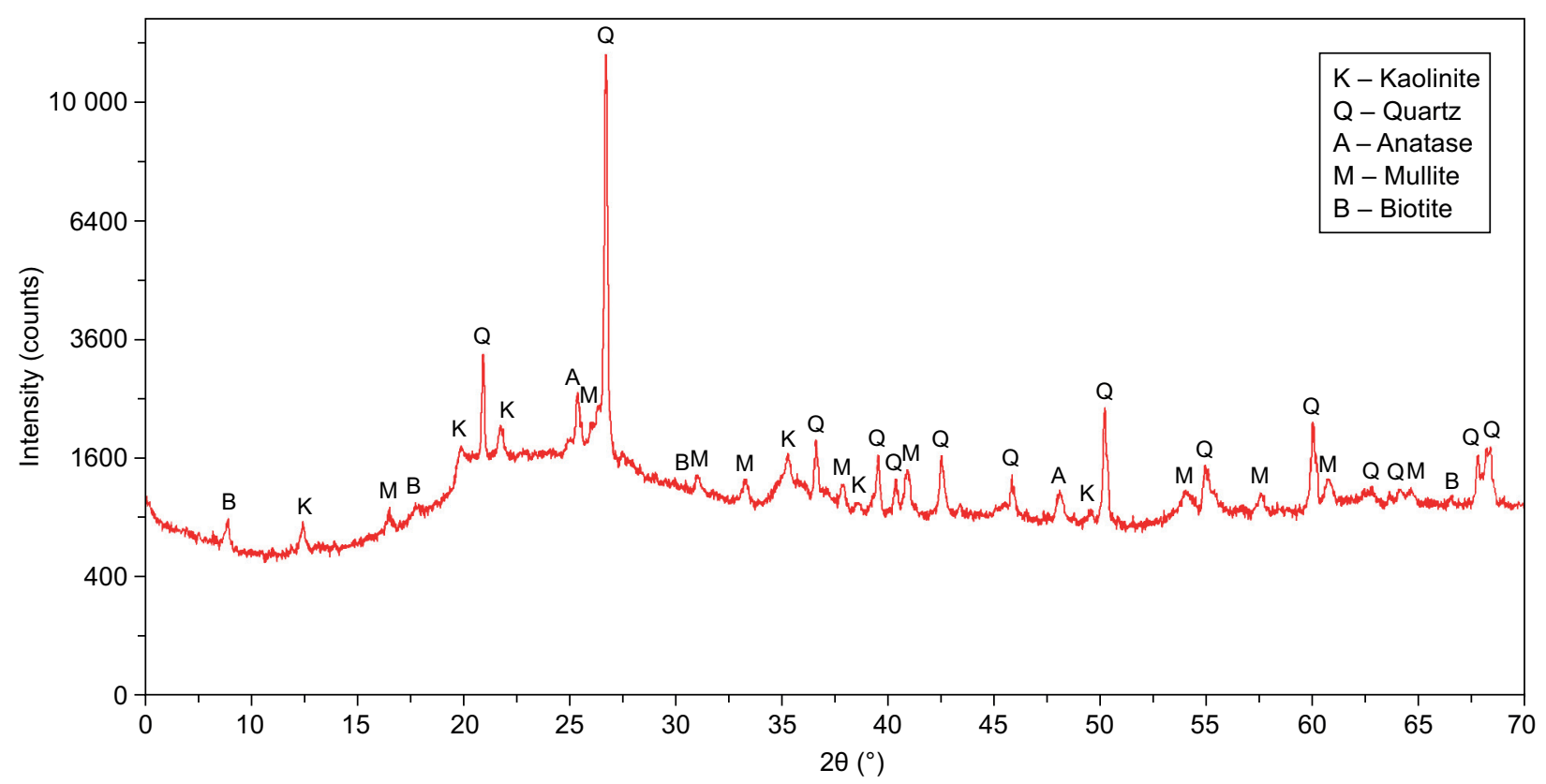

Figure 3. X-ray powder diffraction pattern of the metakaolin Mefisto L05. 
The effect of curing temperature on the properties and structure of geopolymer composite based on potassium silicate and metakaolin

Table 4. Amount of amorphous phase and identified minerals in the geopolymer and the raw materials.

\begin{tabular}{ccc}
\hline Mefisto L05 & Thermal silica & Geopolymer $80^{\circ} \mathrm{C}$ \\
\hline Approx. 85 \% amorphous phase & Almost amorphous phase & Almost amorphous phase \\
\hline Approx.7 \% Quartz & & \\
\hline Remained crystalline phase & Identified traces of & Identified traces of Quartz, \\
with identified traces of Mullite, & $\mathrm{ZrO}_{2}$ hexagonal & Bexagonal, Mullite, \\
Anatase, Biotite and Kaolinite & & Biotite, Kaolinite and Anatase \\
\hline
\end{tabular}

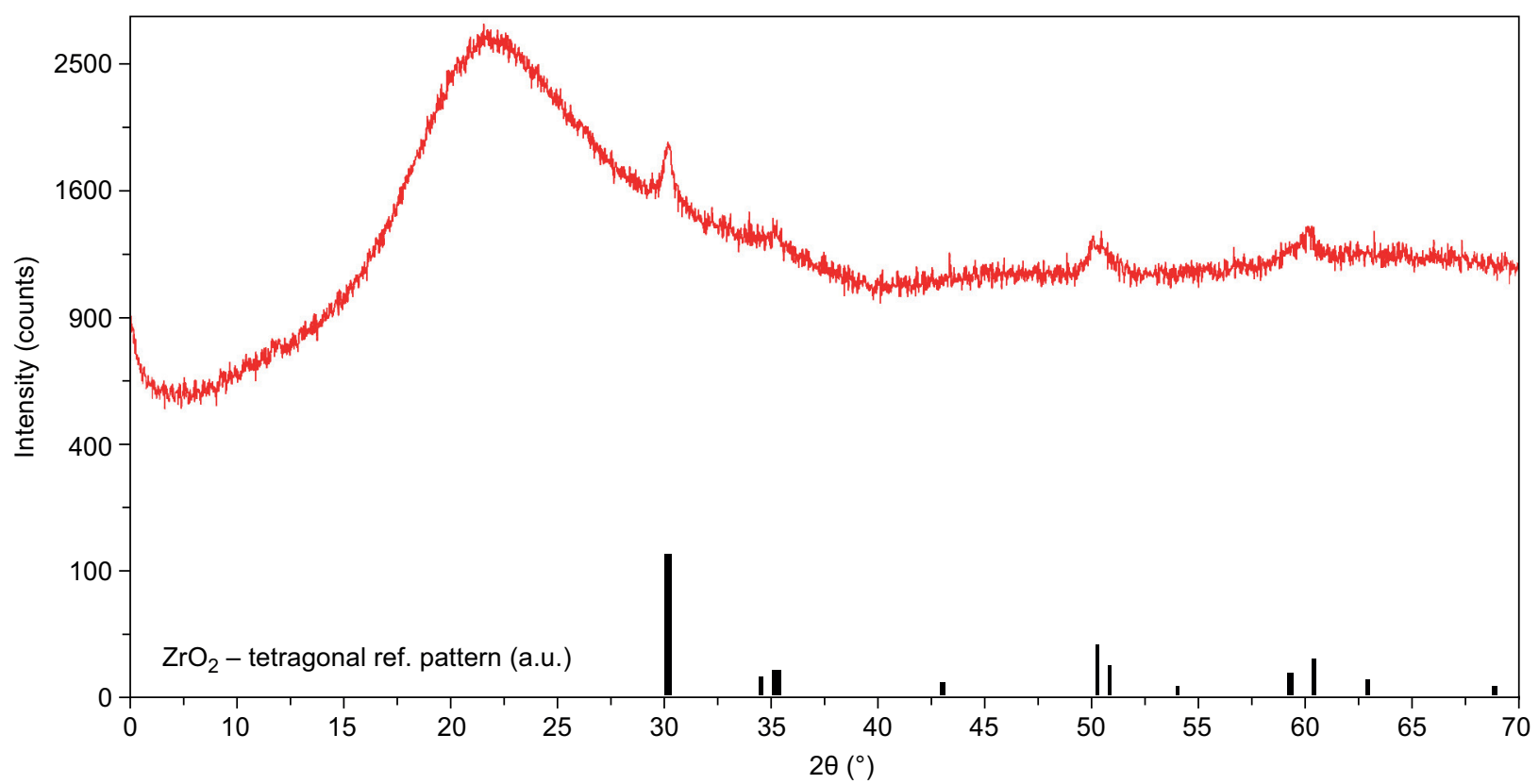

Figure 4. X-ray powder diffraction pattern of the Thermal Silica with a reference pattern of $\mathrm{ZrO}_{2}$ tetragonal.

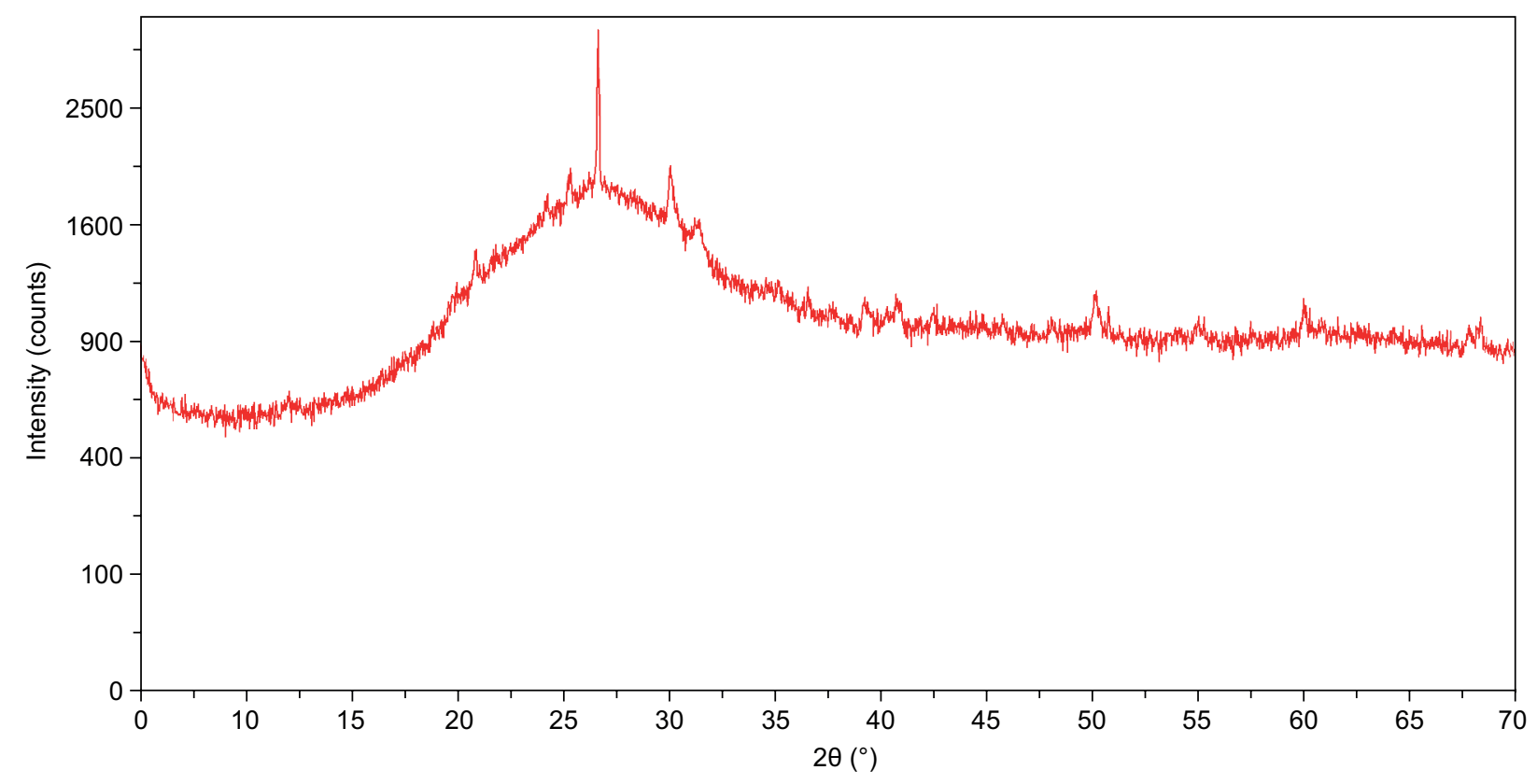

Figure 5. X-ray powder diffraction pattern of the geopolymer cured at $80^{\circ} \mathrm{C}$. 
not detected by X-ray diffraction. The content of $\mathrm{TiO}_{2}$, which shows a signal as anatase in the X-ray diffraction spectrum, was analysed as well as a significant amount of $\mathrm{Fe}_{2} \mathrm{O}_{3}$, which causes a grey colouring of the raw material.

X-ray diffraction was supplemented by the NMR method, which was used to assess the effect of the curing temperature mode according to Table 5 on the change in the structure of the geopolymer resin. In the case of the metakaolin raw material, which was analysed as a reference sample, there is a broad peak for ${ }^{29} \mathrm{Si}$ and ${ }^{27} \mathrm{Al}$ in the spectra, see Figure 7. The peak of $5 \mathrm{ppm}{ }^{29} \mathrm{Al}$ in the metakaolin represents the form of $\mathrm{Al}^{(\mathrm{VI})}$. It was found

Table 5. Curing process of the geopolymer samples for NMR.

\begin{tabular}{llll}
\hline Sample & Stage 1 & Stage 2 & Stage 3 \\
\hline $17053-1$ & Mefisto L05 & & \\
\hline $17053-2$ & $23^{\circ} \mathrm{C} / 14$ days* & & \\
\hline $17053-3$ & $23^{\circ} \mathrm{C} / 24 \mathrm{~h}^{*}$ & $60^{\circ} \mathrm{C} / 24 \mathrm{~h}$ & \\
\hline $17053-4$ & $23^{\circ} \mathrm{C} / 24 \mathrm{~h}^{*}$ & $80^{\circ} \mathrm{C} / 24 \mathrm{~h}$ & \\
\hline $17053-5$ & $23^{\circ} \mathrm{C} / 24 \mathrm{~h}^{*}$ & $80^{\circ} \mathrm{C} / 24 \mathrm{~h}$ & $100^{\circ} \mathrm{C} / 24 \mathrm{~h}$ \\
\hline & & $80-90-100-110-$ \\
$17053-6$ & $23^{\circ} \mathrm{C} / 24 \mathrm{~h}^{*}$ & $80^{\circ} \mathrm{C} / 24 \mathrm{~h}$ & $\begin{array}{l}-120-130-140- \\
\text { every } 2 \mathrm{~h}\end{array}$ \\
\hline
\end{tabular}

* Kept in sealed plastic packaging that with an increasing curing temperature, the peak of $50-80 \mathrm{ppm}$, corresponding to $\mathrm{Al}^{(\mathrm{IV})}$, increased as well. However, traces of $\mathrm{Al}^{(\mathrm{VI})}$ still remain. The corresponding signal for ${ }^{29} \mathrm{Si}$ indicates the initial representation of $\mathrm{Q}^{4}$ (3/4Al), $\mathrm{Q}^{4}(2 \mathrm{Al})$ and $\mathrm{Q}^{4}(1 \mathrm{Al})$. The system transformed into the prevailing representation of $\mathrm{Q}^{4}(2 \mathrm{Al})$ depending on the increasing temperature. It means that the system underwent a structural change consisting of the involvement of $\mathrm{Al}^{(\mathrm{IV})}$ tetrahedra in the structure; the structure of $\mathrm{Q}^{4}(2 \mathrm{Al})$ is mostly represented at the maximum degree of curing.

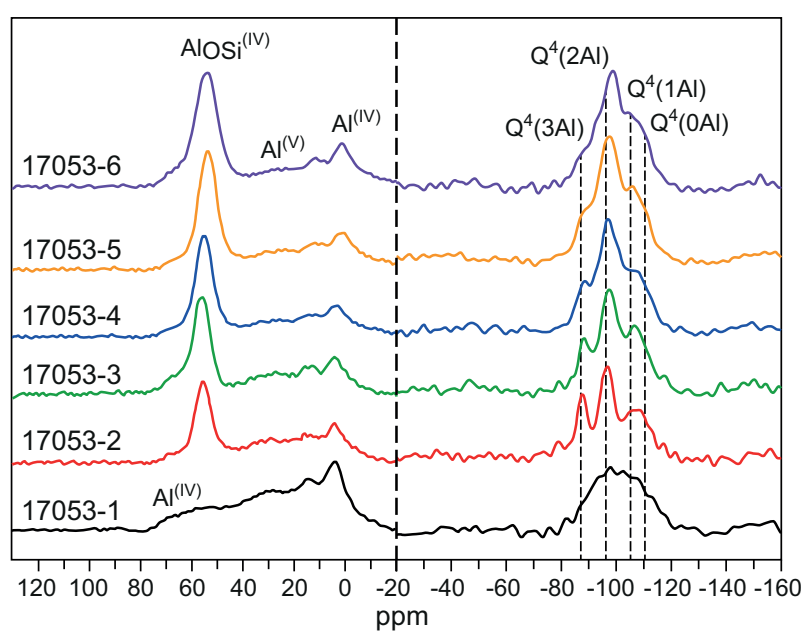

Figure 7. Chemical shift for ${ }^{29} \mathrm{Si}$ and ${ }^{27} \mathrm{Al}$ in the NMR spectra of the samples cured acc. to Table 5 .

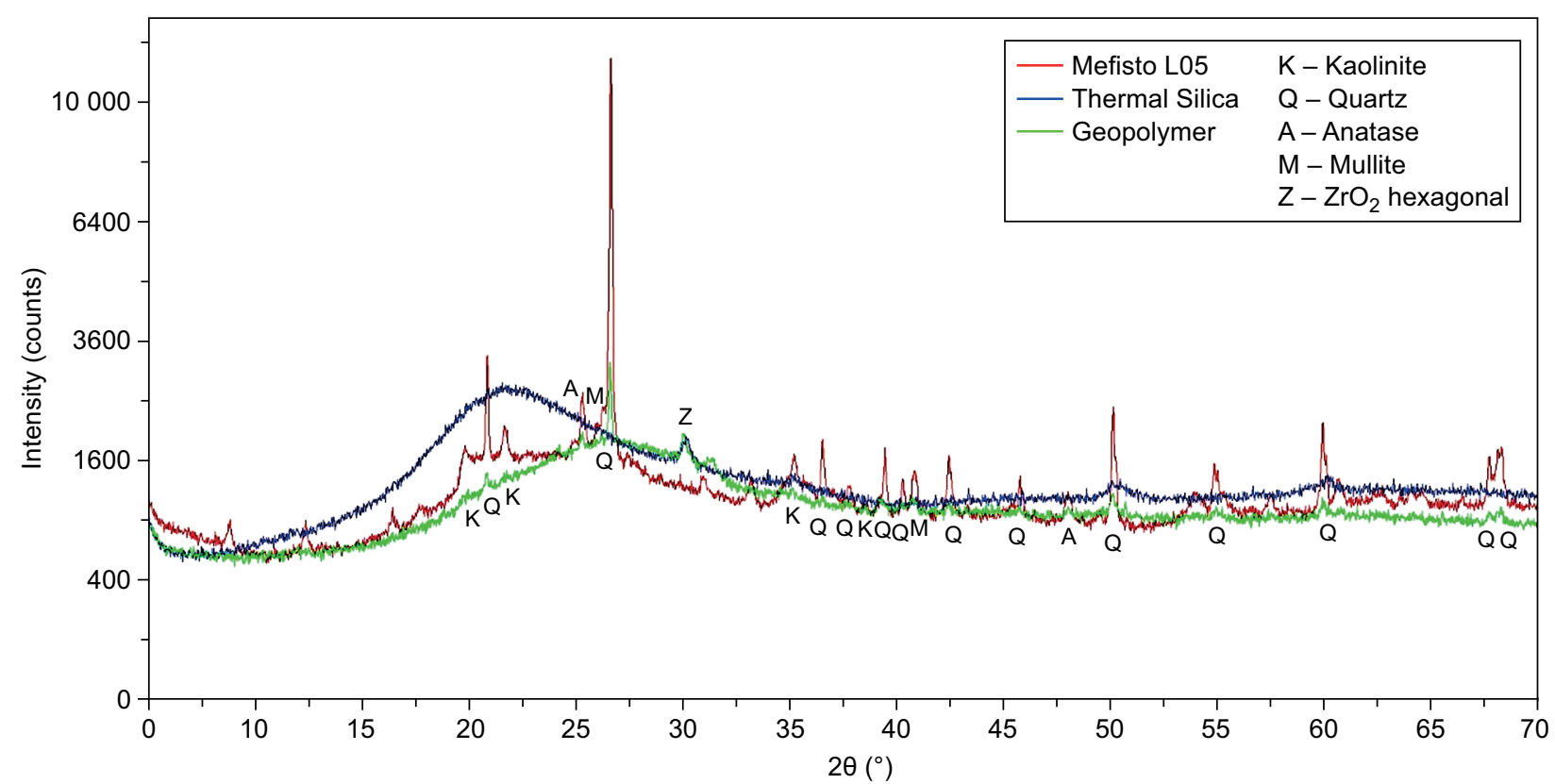

Figure 6. X-ray powder diffraction patterns of the geopolymer cured at $80^{\circ} \mathrm{C}$ - the green curve with markers of identified minerals; compared with the raw materials of the Mefisto L05 and the Thermal Silica as the source of mineral impurities. The matching peaks marked with capital letters. 


\section{CONCLUSIONS}

Our results show that increasing the curing temperature changes the strength properties and the geopolymer structure. It was determined by NMR that aluminium octahedra $\mathrm{Al}^{(\mathrm{VI})}$ are transformed to $\mathrm{Al}^{(\mathrm{IV})}$ tetrahedra and that the coordination of the silicon tetrahedra changes as well. After the initial insignificant distribution of the $\mathrm{Q}^{4}(4 \mathrm{Al}), \mathrm{Q}^{4}(3 \mathrm{Al}), \mathrm{Q}^{4}(2 \mathrm{Al})$ and $\mathrm{Q}^{4}(1 \mathrm{Al})$ structures, the increase in temperature supported the $\mathrm{Q}^{4}(2 \mathrm{Al})$ structure, while the $\mathrm{Q}^{4}(4 \mathrm{Al})$ and $\mathrm{Q}^{4}(3 \mathrm{Al})$ structures were receding and the $\mathrm{Q}^{4}(0 \mathrm{Al})$ structure was virtually not present. This evolution of the structure was accompanied by the increasing resistance to the corrosive effects of hot distilled water. The maximum resistance of the composite was achieved by exposure to a temperature ramp terminated at $170^{\circ} \mathrm{C}$; the weight loss was only $6 \%$ and the storage modulus decreased by $41 \%$, which was the smallest decrement. The predominance of the $\mathrm{Q}^{4}(2 \mathrm{Al})$ structures was confirmed. This is consistent with the idea that aluminium and silicon tetrahedra are interconnected in a functional polymer network. The highest storage modulus, i.e., the highest stiffness, was achieved by primary curing at $80^{\circ} \mathrm{C}$. Curing at higher temperatures caused a small decrease in the storage modulus. X-ray diffraction confirmed that the synthesised geopolymer is an amorphous substance with a minor crystalline phase that originates in the mineral impurities contained in the Burnt Clay Shale raw material. Scanning electron microscopy proved that the geopolymer composite cured at $170^{\circ} \mathrm{C}$ showed a greater tendency to separate the matrix from the fibres compared to the composite cured at $80^{\circ} \mathrm{C}$.

In summary, we have determined two curing temperature modes which provide $\mathrm{CF} /$ geopolymer composites for two types of conditions of use. A geopolymer composite cured at $80^{\circ} \mathrm{C}$ for 18 hours is suitable for use in heat stressed applications, where the use of a common epoxy resin is not possible. The second type of curing proceeds at $80^{\circ} \mathrm{C}$ for 18 hours followed by a two-hour dwell at each temperature, 100, 110, 120, 130, 140, 150, 160 and $170^{\circ} \mathrm{C}$; the resulting geopolymer composite is promising for use in a humid environment.

\section{Acknowledgement}

This result was obtained within the institutional support of the Ministry of Industry and Trade of the Czech Republic for the development of a research organisation (decision No. 12/2017).

\section{REFERENCES}

1. Davidovits J. (2008). Geopolymer Chemistry \& Applications. Institute Géopolymère, Saint Quentin, France. ISBN 9782951482050

2. Barbosa V.F.F., MacKenzie K.J.D., Thaumaturgo C. (2000): Synthesis and characterisation of materials based on inorganic polymers of alumina and silica: sodium polysialate polymers, International Journal of Inorganic Materials, 2, 309-317. doi: 10.1016/S1466-6049(00)00041-6

3. Lippmaa E., Maegi M., Samoson A., Engelhardt G., Grimmer A. R. (1980): Structural studies of silicates by solid-state high-resolution silicon-29 NMR, Journal of American Chemical Society, 102, 4889-4893. doi: 10.1021/ ja00535a008

4. Müller D., Hoebbel D., Gessner W. (1981): 27Al NMR studies of aluminosilicate solutions. Influences of the second coordination sphere on the shielding of aluminium. Chemical Physics Letters, 84, 25-29. doi: 10.1016/00092614(81)85362-6

5. Müller D., Gessner W., Behrens H.-J., Scheler G. (1981): Determination of the aluminium coordination in aluminium-oxygen compounds by solid-state high-resolution 27AI NMR. Chemical Physics Letters, 79, 59-62. doi: 10.1016/0009-2614(81)85288-8

6. Loewenstein W. (1954): The distribution of aluminum in the tetrahedra of silicates and aluminates. American Mineralogist, 39, 92-96.

7. Hung T.D., Louda P., Kroisová D., Bortnovsky O., Xiem N. T. (2011). New Generation of Geopolymer Composite for Fire-Resistance, in: Tesinova P. (Ed.): Advances in Composite Materials - Analysis of Natural and Man-Made Materials. pp. 73-92. Available from: http://www.intechopen.com/books/advances-in-composite-materials-analysisof-natural-and-man-madematerials/new-generation-ofgeopolymer-composite-for-fire-resistance [6.4.2018]

8. Lin T., Jia D., Wang M., He P., Liang D. (2009): Effect of fibre content on mechanical properties and fracture behaviour of short carbon fibre reinforced geopolymer matrix composites. Bulletin of Materials Science, 32, 77-81. doi: 10.1007/s12034-009-0011-2

9. Foden A.J., P. Balaguru, R.E. Lyon, J. Davidovits (1999). Flexural fatigue properties of geopolymer matrix-carbon fiber composite. in: Proceedings of $2^{\text {nd }}$ International conference on geopolymers, pp. 143-154. ISBN 2902933150.

10. Davidovits J., Davidovics M. J. (1991): Geopolymer: Ultra-high temperature tooling material for the manufacture of advanced composites. SAMPE, 36, 1939-1949. Available from: https://www.geopolymer.org/fichiers pdf/ TOOLING.pdf [5.4.2018]

11. Thang X.N., Kroisová D., Louda P., Bortnovský O. Microstructure and flexural properties of geopolymer matrix-fibre reinforced composite with additives of alumina $\left(\mathrm{Al}_{2} \mathrm{O}_{3}\right)$ nanofibers Technical University of Liberec, 2010, pp. 8 [CD-ROM]. ISBN 978-80-7372-638-6.

12. E. Rill, D.R. Lowry, W.M. Kriven (2010). Properties of basalt fiber reinforced geopolymer composites, in Mathur S., Ohji T.(Ed.): Strategic Materials and Computational Design. pp. 57-67. doi:10.1002/9780470944103.ch6 